\title{
The Economic Crisis, Public Sector Pay, and the Income Distribution
}

Tim Callan (ESRI), Brian Nolan (UCD) and John Walsh (ESRI)

Paper for IZA/OECD Conference, Paris, February 2009

\begin{abstract}
An important aspect of the impact of the economic crisis is how pay in the public sector responds - in the face not only of the evolution of pay in the private sector, but also extreme pressure on public spending (of which pay is a very large proportion) as fiscal deficits soar. What are the effects on the income distribution of cutting public sector pay rates or alternative strategies to reduce the public sector pay bill, and how does these vary depending on the evolution of pay in the private sector? This paper investigates these issues using data and a tax-benefit simulation for Ireland, a country which faces a particularly severe fiscal crisis and where innovative measures have already been implemented to claw back pay from public sector workers in the guise of a "pensions levy”, followed most recently by a significant cut in nominal pay rates. The SWITCH tax-benefit model first allows the distributional effects of these measures, which achieved a substantial reduction in the net public sector pay bill, to be teased out. The overall impact on the income distribution, set against alternative scenarios for pay in the private sector, is assessed. This provides empirical evidence relevant to policy choices in relation to a key aspect of household income over which governments have direct influence, while at the same time illustrating methodologically how a tax-benefit model can serve as the base for such investigation.
\end{abstract}




\section{The Economic Crisis, Public Sector Pay, and the Income Distribution}

\section{Introduction}

The economic crisis is impacting most directly on the numbers employed in the private sector and how much they are paid. However, a very important issue is how pay in the public sector responds - in the face not only of the way pay is changing in the private sector, but also the extreme pressure on public spending as fiscal deficits soar. What are the effects on the income distribution of cutting public sector pay rates or alternative strategies to reduce the public sector pay bill, and how do these vary depending on the evolution of pay in the private sector? This paper investigates these issues using data and a tax-benefit simulation for Ireland, a country which faces a particularly severe fiscal crisis and where innovative measures have already been implemented to claw back pay from public sector workers in the guise of a "pensions levy", followed most recently by a significant cut in nominal pay rates in the public sector.

We begin by describing the exceptionally severe nature of the economic crisis for Ireland, which has led to these dramatic policy measures. We then outline the changes in tax and welfare policy implemented in response and report on their distributional impact using conventional tax-benefit simulation model analysis. We then focus on how the same Irish model, the SWITCH tax-benefit model, can be used to analyse the distributional effects of the measures aimed at reducing the public sector pay bill. We first discuss the various rationales advanced for cutting public service pay in the context of the crisis, and describe the structured way in which this was done via a "pensions levy" followed by a graduated set of pay cuts. The overall impact on the income distribution, set against alternative scenarios for pay in the private sector, is assessed. Finally, we discuss the implications for public policy in responding to the crisis. 


\section{Ireland's Exceptionally Severe Economic Crisis}

The rate of economic growth and the increase in numbers employed in Ireland during the so-called "Celtic Tiger" years from 1994 to 2007 were dramatic by any standards, Growth in GNP from 1994 to 2000 was among the highest in the OECD, and while lower from 2001 to 2007 was still substantial; over the whole period it averaged 6\%. By 2007, Ireland's GNP per capita was among the highest in the EU. Jobs growth was also remarkable, with the total number in employment rising by $75 \%$, from 1.2 million to 2.1 million. Unemployment declined very rapidly, from $16 \%$ in 1994 to $4 \%$ by 2000 , staying at that level up to 2007. In-migration was very important in allowing growth to continue at a rapid pace, with a wave of return migration by Irish people who had left for Britain and the USA in the 1980s, followed by substantial numbers from other EU countries, an entirely new phenomenon for Ireland. By 2006-07 net immigration had reached 70,000 per year.

Export growth and foreign direct investment were strong in the earlier part of the boom, but there was an important shift in the drivers of economic growth after about 2000. Exports slowed significantly, with a loss in competitiveness as inflation ran well ahead of the rest of the euro-zone. Domestic sources of demand predominated, the construction sector in particular, with the number of dwelling units being built reaching a peak of almost 90,000 in 2006 - about three times the more usual level. This left the economy highly vulnerable to a slowdown in construction and house-building in particular, in a context where house prices had continued rising very rapidly throughout the period despite the scale of building.

After the onset of the international financial crisis in late 2007, Irish GNP fell by 3\% in volume terms in 2008 as the impact of declining global trade and economic activity was compounded by the bursting of the domestic property bubble. The decline in GNP accelerated to $10 \%$ in 2009, marking Ireland out as one of the OECD countries worst hit by the global economic crisis. Unemployment rose rapidly to exceed $12 \%$ by end-2009, despite the fact that outward migration resumed with both Irish nationals and a significant proportion of recent immigrants from elsewhere leaving to seek work elsewhere. 
Construction activity, having accounted for as much as $14 \%$ of employment at its peak, fell away dramatically as house prices collapsed and commercial construction also stalled.

The slump has had a profound impact on the government's fiscal position, not only due to the downturn in economic activity and increase in unemployment, but also because of the calamitous effect of the property "bust" on tax revenue. The tax base had become highly unbalanced during the boom years, with income tax being cut substantially and replaced by revenue from stamp duties and other taxes on property development and sales revenue that virtually disappeared when the property market ground to a halt. The general government balance (GGB) went from a position of surplus to a deficit of $7 \%$ of GNP in 2008, and in the absence of corrective measures was set to reach 14\% or above in 2009 . The debt to GDP ratio, having fallen to $25 \%$ by 2007 , soared: by end- 2008 it was $44 \%$ and on track to exceed $70 \%$ by end-2009.

Against this background, Irish policymakers had to try to bring the public finances under control while at the same time addressing the severe liquidity and solvency problems facing the banking system - reflecting both the international liquidity "crunch" and the exceptional exposure of Irish banks to property-based loans whose underlying assets had lost much of their value. The measures announced from late 2008 onwards for implementation in 2009 and 2010 include major changes in the tax and social welfare system, whose distributional effects can be readily analysed via what is now standard taxbenefit simulation modelling as we report in Section 3; they further entail changes in the pay of public servants which also have significant distributional implications but pose new analytical challenges, as we discuss in the remainder of the paper.

\section{The Distributional Impact of the Tax and Welfare Response}

Changes to taxes and social transfers constituted one of the main planks in the Irish government's response to the economic and fiscal crisis. Tax and welfare changes are announced in the annual Budget statement, and the Irish government did not begin to seriously address the fiscal implications of the crisis until the Budget for 2009, brought 
forward from the usual December date to October 2008 because of the collapse in tax revenues.. The principal component was the introduction of a new income levy to be applied at the rate of $1 \%$ to gross income up to $€ 100,100$ per annum and $2 \%$ to income in excess of that amount, with none of the allowances or reliefs that apply in the standard income tax system, with the only exception being that social welfare payments are not liable. Social welfare rates for pensioners, unemployed etc. were increased by a little over $3 \%$, in a context where price inflation was falling away (and indeed would turn out to be negative in 2009). As we shall see, this combination implied a remarkably strong redistributive effect, with lower deciles gaining and middle and upper ones losing substantially.

As the scale of the collapse in government revenue became apparent a further set of measures was announced in February 2009 intended to deliver $€ 2$ billion in savings in the year. A central element was a new pension-related payment from public sector workers, graduated to take account of different pay levels in the public service, which we discuss in detail in the next section. A special "emergency” Budget was then announced in April 2009, with substantial further tax increases. The new income levy rates were doubled, to $2 \%$ from $€ 15,028$ to $€ 75,036,4 \%$ up to $€ 174,980$, and a $6 \%$ rate to income in excess of that figure. In addition, the long-standing health levy - similarly applying to gross income and separate from the income tax system - also had its rate double to $4 \%$ (5\% over $€ 75,036$ ), and the ceiling below which pay-related social insurance contributions were payable was increased substantially, from $€ 52,000$ to $€ 75,036 .{ }^{1}$ Savings in social welfare spending were also sought by not having the usual double payment at Christmas, and by halving the universal Early Childcare Supplement payment for children under 6 from 1 May and abolishing it from end-2009. (A replacement scheme is currently being introduced, to provide support for a single year of pre-schooling, much less costly to the State). With the stated aim of incentivising job-seeking, the rate of income support for new claimants aged under 21 was also cut substantially.

\footnotetext{
${ }^{1}$ Other tax changes included ending mortgage interest relief for mortgages over 7 years, increasing the rates of capital gains and capital acquisitions tax from $22 \%$ to $25 \%$, and introducing a new levy on life assurance at the rate of $1 \%$ on premiums.
} 
The final set of tax and welfare responses to the crisis so far were contained in the Budget for 2010 presented in December 2009. The two key elements in this Budget related to expenditure, comprising - quite exceptionally in Irish and international experience significant reductions in nominal rates of social welfare support and public service pay. The cuts in weekly social welfare rates, of the order of $4 \%$, were confined to recipients of working age, with pensioners left untouched. (Unemployment payments for those aged 21-25 were also sharply reduced, following on the cuts for those aged 21 in the previous Budget). In addition, the rates of universal Child Benefit paid every month were cut by $10 \%$, although those dependent on social welfare received a compensating increase in their weekly payment. There were also substantial cuts in nominal rates of pay to workers in the public sector, to be discussed in detail in the next section. On the taxation side, the main innovation was the introduction of a carbon tax on fossil fuels. There were no important changes to income tax or levies, though the intention to work towards a fundamental re-structuring of direct taxation by 2011 was announced, to comprise just two charges on income: income tax, and a new universal social contribution (to replace employee PRSI, the Health Levy and the Income Levy). It is expected that the universal social contribution will be operate with a very wide base and a relatively low rate, while income tax will have a progressive rate structure as at present. (The recommendation of the 2009 Commission on Taxation to introduce a property tax was also accepted in principle, but considerable work was said to be required on the registration of ownership and the valuation of land before it could be implemented.)

The distributional impact of the tax and welfare changes implemented in this series of Budgets can be analysed using the SWITCH tax-benefit simulation model developed and employed in the ESRI (see for example Callan et al., 2009a). The aim is to assess the distributional impact of tax and welfare changes against a benchmark which is "distributionally neutral”, rather than against the non-neutral benchmark implicit in the common budgetary practice of measuring changes against a scenario in which tax and welfare parameters are frozen in nominal terms. A budget indexed to wage growth - or in 
current very unusual circumstances decline - has been shown to approximate a neutral benchmark against which policy changes can be measured, and this is what we use here.

Figure 1: Distributive Impact of Tax and Welfare Policy 2009-2010, relative to indexation in line with $5 \%$ fall in wages

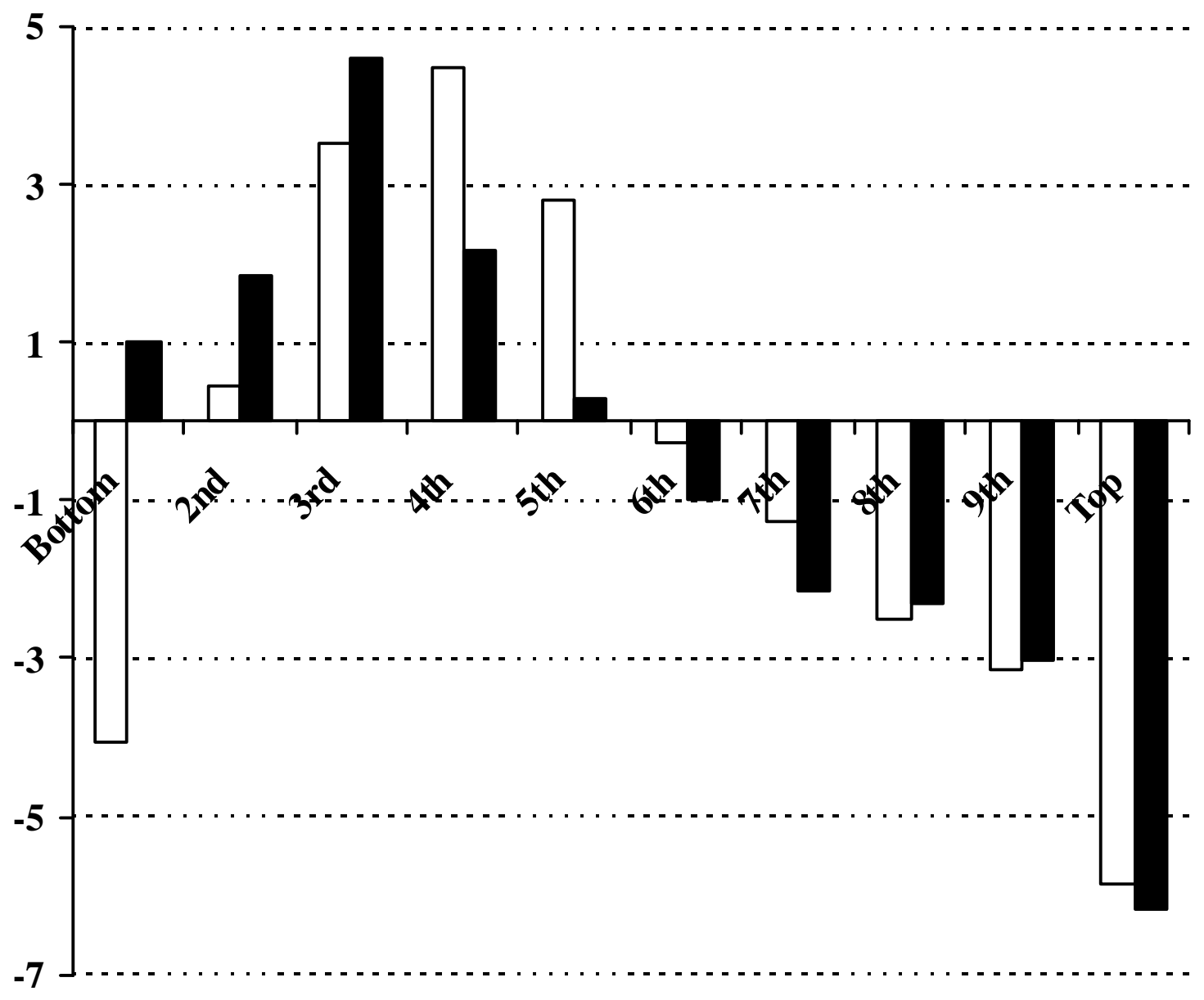

Figure 1 shows the results of such a distributional analysis for the two Budgets for 2009 and the recent Budget for 2010. The impact on those at lowest incomes differs depending on the unit of analysis, that is whether the family or the broader household is taken to be 
the income sharing unit. The poorest family units see a drop in income of about 4 per cent, but the average income of the poorest households rises by about 1 per cent. There is also a gap, though less marked, for the second decile. The main factor behind these results is the sharp reduction in unemployment assistance payments for young unemployed, aged under 25. Many of these are living with their parents. On a family unit basis, they are assessed as separate units, have incomes placing them at the bottom of the distribution, and the falls of $25 \%$ and $50 \%$ in their payment rates have a sharp impact. On a household unit basis, incomes of their parents or other family members may place the household higher up the distribution, and the percentage impact of the reduction in unemployment payments is moderated by the presence of other incomes. On either basis, there are gains of between 3 and 4 per cent for the third quintile - which includes substantial numbers of those on State pensions, which were not cut.

For the upper half of the distribution, results on a family unit and household basis are much closer. There have been substantial falls for the top end of the income distribution (about 5 per cent for both households or family units) and for deciles 8 and 9 (losses of about 3 per cent). These losses arise mainly from the income taxes and levies imposed in April 2009’s Supplementary Budget.

Table 1 gives a different perspective on how the burden of adjustment is distributed, distinguishing between family units on the basis of income source (employed, unemployed, retired, other) and marital status (single, couples with one or two earners) and family status (with/without children). Once again the baseline scenario is policy adjusted in line with a $5 \%$ fall in average earnings.

Those with employment income lose between 2 and 3 per cent of their disposable income if they have no children, and between 4 and 5 per cent if they have children. Employed lone parents, whose income would often combine a welfare payment with employment income are an exception, with average incomes in line with the baseline of 5 per cent negative indexation. The tax and levy increases are the main factors affecting those 
without children, while those with children are, in addition, affected by the 10 per cent cut in universal child benefits.

Families depending mainly on social welfare incomes fared significantly better. This reflects the fact that welfare benefits were initially raised, and then cut, leaving them on balance close to their initial levels - as against a baseline of a 5 per cent cut. For example, couples with an unemployed person, and no employee, have incomes between 3 and 4 per cent above the baseline level. Retired couples have incomes 4 per cent above the benchmark provided by negative indexation, while single retired persons fare even better, with incomes at 6 per cent above the benchmark. This reflects the fact that old age benefits were raised by just over 3 per cent, and not cut subsequently. Also occupational pension incomes - in the public sector and elsewhere - typically did not fall.

Table 1: Impact of tax and welfare changes across family types

\begin{tabular}{lc}
\hline Family Unit Type & \% change in disposable income \\
\hline Single Employed without Children & -2.2 \\
Employed Lone Parent & -0.1 \\
Single Earner Couple without Children & -1.9 \\
Single Earner Couple with Children & -4.1 \\
Dual Earner Couple without Children & -3.2 \\
Dual Earner Couple with Children & -5.3 \\
Single Unemployed without Children & -5.3 \\
Non-Earning Lone Parent & 2.1 \\
Non-Earning Couple (>= 1 UE) no Kids & 3.7 \\
Non-Earning Couple (>= 1 UE) with Kids & 3.5 \\
Single Retired Tax Unit & 6.2 \\
Retired Couple & 4.0 \\
All Other Tax Units & 1.8 \\
All & -2.1 \\
\hline
\end{tabular}

\section{The Focus on Public Sector Pay}

As difficult decisions with respect to taxation and welfare were being made, the issue of public sector pay came centre-stage in the Irish public policy debate. At least three distinct strands of argument can usefully be distinguished in what became an exceptionally contentious debate that, as we shall see, culminated in an outcome that is 
unique for Ireland and quite exceptional across OECD countries: the implementation of substantial reductions in pay rates for public servants.

The first line of argument starts with the role of pay more generally in competitiveness, overall economic performance and growth. As already noted, concern about the competitiveness of Irish exports being eroded by relatively rapid wage and price increases had emerged well before the crisis hit. With domestic drivers of growth having collapsed and unemployment rising rapidly, the need to restore competitiveness has come to the fore. As a member of the euro-zone devaluation is not an option, so squeezing down costs in general and pay costs in particular is a central plank in the government's macroeconomic strategy. Despite widespread reports of pay cuts in the private sector there is considerable uncertainty about how deep and pervasive these have actually been Depending on how one interprets the evidence in that respect, the competitiveness argument is then either a) reductions in public sector pay should follow those in the private sector, both from an equity perspective and to reduce the costs to business associated with financing the public sector; or b) private sector pay needs to fall more but policymakers have few levers allowing them to directly influence it, so public pay cuts provide one way to lead private sector wages down and thus reduce wage costs for producers.

The second, interrelated argument is that public sector pay had already got out of line with that in the private sector during the boom, due to the combination of the national pay agreements negotiated under the Ireland's Social Partnership process (in operation since 1987), together with special "Benchmarking” and associated awards to public servants on the basis that their pay had lagged behind their private sector counterparts. The key Public Service Benchmarking Body Report (2002) provided no evidence that this was the case, and academic studies suggested that public sector workers enjoyed a wage premium at that time (Boyle, McElligot and O’Leary, 2004). More recently, studies by Kelly, McGuinness and O'Connell (2009a, b) have been particularly influential in suggesting that the public sector premium for all employees rose sharply from 2003 to 2006, by 12 
percentage points on average. ${ }^{2}$ Quantile regression indicated that this advantage was greatest for public sector employees at the lower end of the earnings distribution and also varied widely across sub-sectors and occupations - being lowest in the central Civil Service and local authorities and highest in education and for police and prison officers. The Irish public sector premia are high compared with those estimated for other countries, as presented in for example Gregory and Borland (1999), Lucifora and Meurs (2006). There has been some argument over the data and methodology employed, ${ }^{3}$ and a heated public debate, but the notion that pay in the public sector was "out of line" particularly in the light of the generous pension arrangements they generally enjoyed at a time when private sector occupational pensions were under severe pressure due to the falls in asset values - was clearly an important part of the context in which the policy response to the fiscal crisis unfolded.

The final, and in some sense the most straightforward, argument arises simply from that crisis. With wages and salaries one of the most important elements in public expenditure, it has been argued that the scale of the deterioration in the public finances left the government with no choice about reducing the public sector wage bill. If that is accepted - and even the trade unions ended up reluctantly doing so - then the next stage in the argument is that it would be preferable to achieve those reductions through cuts in pay rates rather than reductions in numbers, which would add to unemployment which was already rising sharply as we saw earlier.

Some combination of these arguments led to two measures which had the effect of substantially reducing the take-home pay of public sector workers alone. The first was the

\footnotetext{
${ }^{2}$ Kelly et al (2009a) show the premium increasing from $10 \%$ to $22 \%$, while Kelly et al (2009b) present estimates of $14 \%$ and $26 \%$ - both employ the same data but differ in the definition of what constitutes public sector and in the details of the analytical methods/specifications employed.

${ }^{3}$ These focused in particular on the appropriateness of including controls for organizational size and trade union membership, (see for example Central Statistics Office (2009)
} 
introduction of a public sector pension levy ${ }^{4}$ in March 2009, announced together with the fact that public sector pay rises due to be paid would not go ahead. Under the terms of the Financial Emergency Measures in the Public Interest Bill 2009, as amended in the April 2009 Budget, the first $€ 15,000$ of earnings was exempt from the levy, which was then charged at rates of:

- $5 \%$ on next $€ 5,000$ of earnings,

- $10 \%$ on earnings between $€ 20,000$ and $€ 60,000$ and

- $10.5 \%$ on earnings above $€ 60,000$.

The justification advanced was

The second measure directed at public sector workers, contained in the December 2009 Budget for 2010, announced that public service salaries will be reduced as follows:-

- $5 \%$ on the first $€ 30,000$ of salary

- $7.5 \%$ on the next $€ 40,000$ of salary

- $10 \%$ on the next $€ 55,000$ of salary

This produces overall reductions in salaries ranging from $5 \%$ to just under $8 \%$ in the case of salaries up to $€ 125,000$. Salaries above that level will be adjusted in line with the recommendations of the Review Body on Higher Remuneration in the Public Sector. This will produce reductions ranging from $8 \%$ on salaries of up to $€ 165,000,12 \%$ on salaries up to $€ 200,000,15 \%$ on salaries of $€ 200,000$ or more and $20 \%$ in the case of the Taoiseach. These measures were expected to lead to annual savings of over $€ 1$ billion. Importantly, those retired from public sector employment and in receipt of pensions linked to current pay in the grade from which they retired - standard practice in the Irish public service - were not to see their pensions cut in line with that pay.

\footnotetext{
${ }^{4}$ The formal name for the levy is the "Pension-related Deduction" (PRD) but it is much more widely referred to as the public service pension levy.
} 


\section{Distributional Impact of Public Sector Pay Cuts}

Both the public sector pension levy introduced in February 2009, and the pay cuts introduced in Budget 2010 were explicitly structured so as to have least impact at low pay levels and greatest impact at high pay levels. A flat percentage change in gross income would have had greatest impact on the net incomes of those with incomes too low to pay tax, a lesser impact on those paying some tax, and a rising proportionate impact as incomes rose. (Callan et al., 2009b) This arises essentially because of the progressive nature of the income tax system - it takes a higher proportion of income as income increases, so that when incomes are reduced, the net impact on take-home pay is not equal but shaped by the marginal rate structure.

In Figure 2 we look at the impact of these measures (pension levy and pay cuts) on net disposable incomes. We show the proportionate impact on the disposable income of the decile, and later will consider the impact on those affected (public sector workers). We identify first of all the net impact of the pay cuts/pension levy against a "no change" or frozen wage scenario, but then examine the impact relative to a 5 per cent cut in public sector wages. The latter can be interpreted as a parallel with the "distributionally neutral" scenario, in which public sector workers experience the same wage reduction as the average private sector worker.

As there are few public sector employees in the bottom 4 deciles of family unit income, we aggregate over these and find that the net impact on these deciles is close to zero. The proportionate fall in disposable income rises gradually to about 1 per cent for the eighth decile, 2 per cent for the $9^{\text {th }}$ deciles and 3 per cent for the top decile. Compared to a baseline with a 5 per cent pay cut - an estimate of the average fall in the private sector - a similar pattern applies, but with the fall reaching 1 per cent at the $9^{\text {th }}$ decile and a maximum of 2 per cent for the top decile. 
Figure 2: Distributional impact of public sector pay cuts relative to "wage freeze" and 5\% pay cut

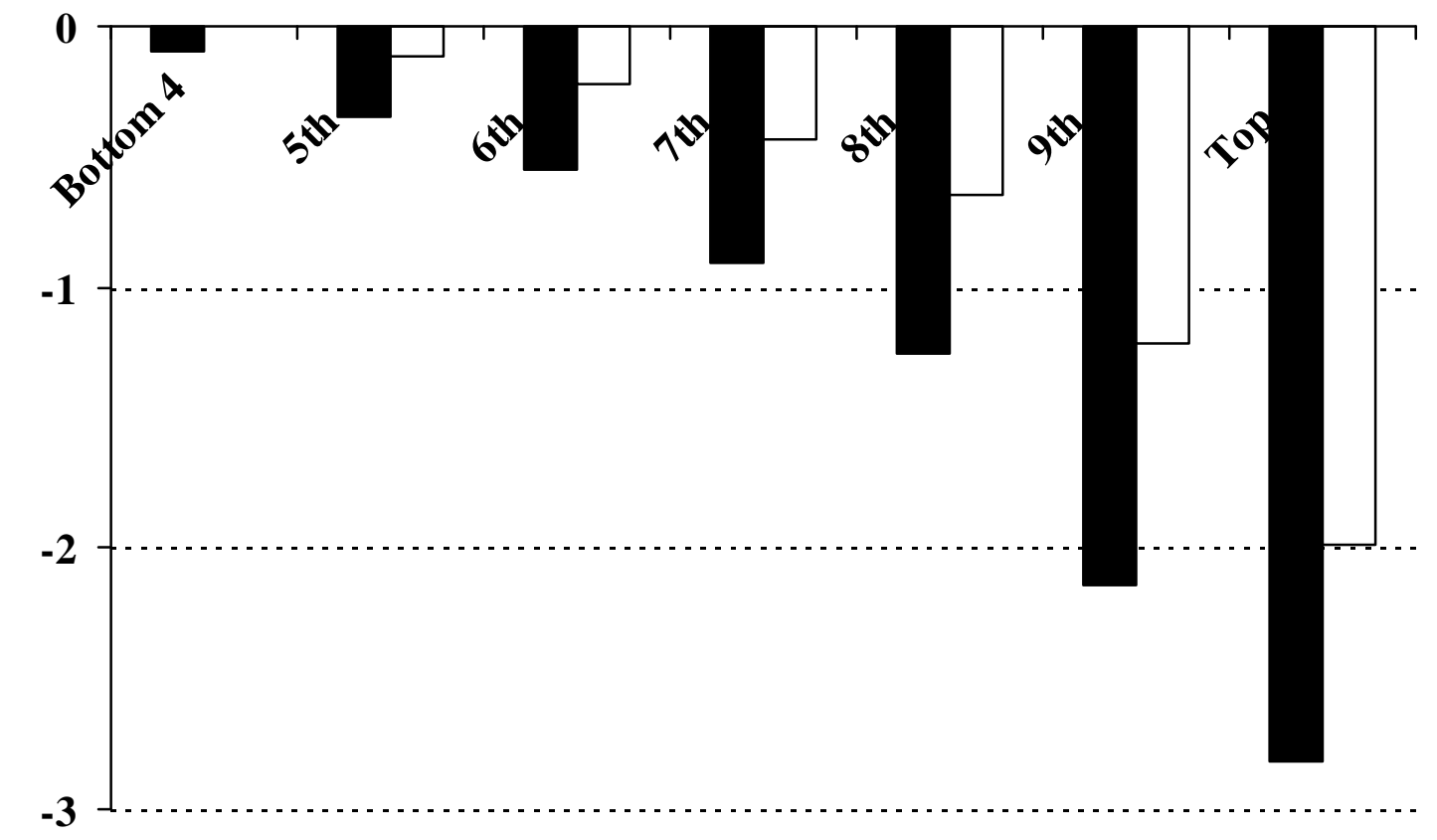

Above, we were interested in the impact of the changes on average decile income. It is also of interest to know the extent of the impact on those affected, classified by decile. We undertake this analysis against the counterfactual of a 5 per cent cut in pay rates, in the public sector as well as the private sector. Analysis on this basis shows losses of 1 to 2 per cent for the small number of family units containing a public sector worker and having disposable incomes in the lowest 4 deciles. Losses rise to around 3 per cent for family units containing one or more affected workers in deciles 5 to 8, and to 4 and 5 per cent respectively for those in the ninth and tenth deciles. Recall, these losses come on top of the loss from a 5 per cent flat rate cut in pay.

Three main factors contribute to the strongly progressive impact of the public sector pay cuts, over and above the fact that pay is itself a key driver of the income distribution:

1. The skill mix of the public sector means that public sector workers tend to have higher pay than private sector workers on average. 
2. Growth in the public sector premium reinforces this tendency, so that public sector workers are more likely to be found in highly paid employment.

3. The pension levy and pay cut have each been structured in a way designed to give a progressive impact.

Work on the public sector premium has found that it tends to be greatest at low incomes, and least at high incomes. The structure of pay cuts as implemented may help to reduce the premium at low pay, but could result in a negative premium at higher earnings levels. This suggests that there are limits to the scope for further pay cuts along the lines of those already implemented.

\section{Conclusions and Implications}

Cutting public service pay represent an instrument open to governments as they respond to the economic crisis, albeit one that would only be potentially feasible in such extreme circumstances. As well as the fiscal and macroeconomic effects, the assessment of such a policy vis-a-vis alternatives should take distributional implications into account. The analysis of the distributional pattern associated with recent significant cuts in public service pay in Ireland provides empirical evidence relevant to policy choices in relation to a key aspect of household income over which governments have direct influence, while at the same time illustrating methodologically how a tax-benefit model can serve as the base for such investigation.

Given that public employees are predominantly located in the middle and upper parts of the income distribution, cutting their pay will generally have the immediate effect of reducing inequality. This might make it appear an attractive policy from a purely distributional perspective - certainly compared with welfare cuts. However, it is clearly important in the medium to longer term that pay rates in the public sector are of a sufficient level to attract and retain individuals with the qualifications and skills required to deliver good quality public services. Furthermore, both the way in which pay cuts are structured - flat-rate or graduated - and the counterfactual against which they are assessed will be key to the conclusions reached about distributional impact. 
In conclusion, it may be worth highlighting the distributional implications of the way in which pensions for public sector workers are treated if pay for current workers is constrained or reduced. Pensions of public sector retirees grew in line with the pay of public servants during Ireland's boom years. The latter part of that boom has proved unsustainable, and incomes of workers and social welfare recipients are adjusting to the changed circumstances. As "pay parity" operated to the benefit of retirees in the boom times, one could argue that it should operate in a symmetrical fashion as the pay of those in public sector employment is reduced. 


\section{References}

Boyle, G.R., McElligot, R. \& O’Leary, J. 2004. “Public-Private Wage Differentials in Ireland, 1994-2001”, ESRI Quarterly Economic Commentary, Special Article. Summer 2004. Dublin: Economic and Social Research Institute.

Callan, T., Keane, C. and Walsh, J. R., 2009 “Tax Reform: Selected Issues” in T. Callan (ed.) Budget Perspectives 2010, Dublin: The Economic and Social Research Institute.

Callan, T., Keane, C. and Walsh, J. R., 2009 Pension Policy: New Evidence on Key Issues, Dublin: The Economic and Social Research Institute Research Series No. 14.

Kelly, E., McGuinness, S., \& O’Connell, P.J., 2009. “Benchmarking, Social Partnership and Higher Remuneration: Wage Settling Institutions and the Public-Private Sector Wage Gap in Ireland”, Economic and Social Review 40 (3): 339-370.

Kelly, E., McGuinness, S., \& O’Connell, P.J., 2009. “The Public-Private Sector Pay Gap in Ireland: What Lies Beneath?” ESRI Working Paper 321. 